\title{
KEIDEMPOTENAN DARI KOMBINASI LINIER PADA MATRIKS IDEMPOTEN DAN MATRIKS T-POTEN YANG KOMUTATIF
}

\author{
LATHIFA SUCI NOVIANA, YANITA, MONIKA RIANTI HELMI \\ Program Studi S1 Matematika, \\ Fakultas Matematika dan Ilmu Pengetahuan Alam, Universitas Andalas, \\ Kampus UNAND Limau Manis Padang, Indonesia. \\ email : lathifasuci2311@gmail.com,yanita@sci.unand.ac.id, monikariantihelmi@sci.unand.ac.id
}

Diterima 15 Desember 2020 Direvisi 29 Desember 2020 Dipublikasikan 12 Januari 2021

\begin{abstract}
Abstrak. Misal $A$ adalah matriks idempoten $\left(A^{2}=A\right)$ dan $B$ adalah matriks $t$-poten $\left(B^{t}=B\right)$ untuk semua bilangan bulat positif $t>1$ dan $A B=B A$. Penelitian ini akan memperlihatkan semua pasangan $c_{1}, c_{2}$ bilangan kompleks taknol sehingga kombinasi linier $c_{1} S^{-1} A S+c_{2} S^{-1} B S$ adalah idempoten.
\end{abstract}

Kata Kunci: Matriks Idempoten, Matriks T-Poten, Diagonalisasi.

\section{Pendahuluan}

Himpunan matriks yang memiliki entri-entri bilangan kompleks, yang terdiri dari $n$ baris dan $n$ kolom dapat disimbolkan dengan $\mathbb{C}_{n \times n}$. Suatu matriks $A$ dikatakan idempoten apabila $A$ dikalikan dengan dirinya sendiri merupakan matriks itu sendiri $\left(A^{2}=A\right)$, dikatakan tripoten apabila $A^{3}=A$, dan dikatakan $t$-poten jika $A^{t}=A$.

Jika $A$ dan $B$ komutatif $(A B=B A)$, dimana $A$ adalah matriks idempoten dan $B$ adalah matriks $t$-poten, maka $A$ dan $B$ keduanya dapat didiagonalisasi secara simultan, terdapat matriks nonsingular $S$ sedemikian sehingga $c_{1} S^{-1} A S+c_{2} S^{-1} B S$ adalah matriks idempoten. Pada tulisan ini akan dikaji kembali [4] terkait keidempotenan dari kombinasi linier pada matriks idempoten dan matriks $t$-poten yang komutatif.

\section{Landasan Teori}

\subsection{Diagonalisasi Matriks}

Definisi 2.1. [3] Suatu matriks $A, B$ dan $S$ berukuran $n \times n$ dikatakan similar jika terdapat suatu matriks invertibel $S$ sedemikian sehingga

*penulis korespondensi 


$$
B=S^{-1} A S .
$$

Teorema 2.2. [3] Misalkan matriks $A$ dan $B$ berukuran $n \times n$, dan misalkan matriks $A$ similar ke matriks $B$, maka $A$ dan $B$ memiliki nilai eigen yang sama. Jika $B$ adalah matriks diagonal, maka entri diagonal utamanya adalah nilai eigen dari $A$.

Definisi 2.3. [1] Suatu matriks $A$ berukuran $n \times n$ dikatakan dapat didiagonalkan jika terdapat suatu matriks invertibel $S$ sedemikian sehingga $S^{-1} A S$ adalah matriks diagonal. Matriks $S$ dikatakan mendiagonalkan A.

Definisi 2.4. [4] Dua buah matriks kompleks $A$ dan $B$ dikatakan dapat didiagonalkan secara simultan jika terdapat suatu matriks nonsingular $S$ sedemikian sehingga $S^{-1} A S$ dan $S^{-1} B S$ keduanya diagonal.

Teorema 2.5. [4] Misalkan matriks $A$ dan matriks $B$ yang berukuran $n \times n$ dapat didiagonalisasi, maka $A$ dan $B$ komutatif jika dan hanya jika keduanya dapat didiagonalisasi secara simultan.

\subsection{Matriks Idempoten}

Definisi 2.6. [4] Suatu matriks A berukuran $n \times n$ dikatakan matriks idempoten jika

$$
A^{2}=A
$$

Teorema 2.7. [3] Misalkan matriks A berukuran $n \times n$, maka $A$ adalah idempoten jika dan hanya jika nilai eigennya adalah 0 atau 1.

Definisi 2.8. [4] Suatu matriks $B$ berukuran $n \times n$ dikatakan matriks t-poten jika dan hanya jika untuk semua bilangan bulat positif $t$ memenuhi $B^{t}=B$.

Teorema 2.9. [5] Misalkan $B$ adalah matriks kompleks berukuran $n \times n$, maka $B^{k+1}=B$ untuk $k=2,3, \ldots$ jika dan hanya jika $B$ dapat didiagonalisasi dan nilai eigen dari $B$ adalah $\lambda=0$ atau $\lambda=\sqrt[k]{1}$.

\section{Pembahasan}

\subsection{Keidempotenan dari Kombinasi Linier pada Matriks Idempoten dan Matriks T-Poten yang Komutatif}

Teorema 3.1. [4] Misalkan A dan B adalah matriks kompleks taknol dengan entrientri di himpunan bilangan kompleks $\mathbb{C}$, sedemikian sehingga $A^{2}=A, B^{k+1}=B$ untuk $k=2,3 . \cdots$ dan $A B=B A$. Asumsikan bahwa:

1) A dan $B$ similar secara simultan dengan matriks $A_{1} \oplus O$ dan $B_{1} \oplus B_{2}$, atau dengan matriks $A_{1} \oplus A_{2}$ dan $B_{1} \oplus B_{2}$ dimana $A_{1}, A_{2}, B_{1}$ dan $B_{2}$ adalah sub matriks dari matriks $A$ dan $B$,

2) B memiliki setidaknya dua nilai eigen taknol yang berbeda, dan

3) $c_{1}, c_{2} \in \mathbb{C}, c_{1} \neq c_{2} \neq 0$, 
maka terdapat matriks nonsingular $S$ sedemikian sehingga $c_{1} S^{-1} A S+c_{2} S^{-1} B S \equiv C$ adalah matriks idempoten yang dalam hal ini matriks $C$ berbentuk salah satu dari yang berikut :

$$
\begin{aligned}
& \text { 1) } \frac{v}{v-u}\left[\begin{array}{ll}
I & 0 \\
0 & I
\end{array}\right]+\frac{1}{u-v}\left[\begin{array}{cc}
v I & 0 \\
0 & u I
\end{array}\right]=\left[\begin{array}{ll}
0 & 0 \\
0 & I
\end{array}\right], \\
& \text { 2) }-u v^{-1}\left[\begin{array}{ll}
I & 0 \\
0 & 0
\end{array}\right]+v^{-1}\left[\begin{array}{cc}
u I & 0 \\
0 & v I
\end{array}\right]=\left[\begin{array}{ll}
0 & 0 \\
0 & I
\end{array}\right], \\
& \text { 3) }\left(1-u v^{-1}\right)\left[\begin{array}{ll}
I & 0 \\
0 & 0
\end{array}\right]+v^{-1}\left[\begin{array}{cc}
u I & 0 \\
0 & v I
\end{array}\right]=\left[\begin{array}{ll}
I & 0 \\
0 & I
\end{array}\right], \\
& \text { 4) }\left[\begin{array}{lll}
I & 0 & 0 \\
0 & I & 0 \\
0 & 0 & 0
\end{array}\right]+v^{-1}\left[\begin{array}{ccc}
-v I & 0 & 0 \\
0 & 0 & 0 \\
0 & 0 & v I
\end{array}\right]=\left[\begin{array}{lll}
0 & 0 & 0 \\
0 & I & 0 \\
0 & 0 & I
\end{array}\right] \text { jika } k=2, \\
& \text { 5) } \varepsilon\left[\begin{array}{lll}
I & 0 & 0 \\
0 & I & 0 \\
0 & 0 & 0
\end{array}\right]+\varepsilon^{-1} u^{-1}\left[\begin{array}{ccc}
\varepsilon^{-1} u I & 0 & 0 \\
0 & u I & 0 \\
0 & 0 & \varepsilon u I
\end{array}\right]=\left[\begin{array}{lll}
0 & 0 & 0 \\
0 & I & 0 \\
0 & 0 & I
\end{array}\right] \text { jika } k=6,
\end{aligned}
$$

dimana $u, v$ adalah akar-akar dari $\sqrt[k]{1}$ untuk suatu $k=2,3, \cdots, u \neq v$, dan $\varepsilon=$ $\frac{1}{2} \pm \frac{\sqrt{3}}{2} i$.

Bukti. Misalkan $A$ adalah matriks idempoten, yaitu $A^{2}=A$, maka nilai eigen dari matriks idempoten adalah $\lambda=0$ atau $\lambda=1$. Misalkan $B$ adalah matriks $t$-poten, yaitu $B^{k+1}=B$ untuk suatu $k=2,3, \cdots$, maka $B$ dapat didiagonalisasi dan nilai eigen dari matriks $B$ adalah $\lambda=0$ atau $\lambda=\sqrt[k]{1}$.

Misalkan $A$ dan $B$ komutatif, maka $A$ dan $B$ dapat didiagonalisasi secara simultan. Oleh karena $A$ dan $B$ dapat didiagonalisasi secara simultan, maka terdapat matriks nonsingular $S$ sedemikian sehingga $S^{-1} A S$ dan $S^{-1} B S$ keduanya diagonal. Asumsikan bahwa matriks $A$ dan $B$ similar secara simultan dengan matriks $A_{1} \oplus O$ dan $B_{1} \oplus B_{2}$ secara berturut-turut. Misalkan

$$
S^{-1} A S=\left[\begin{array}{ccc}
1 & & 0 \\
& \ddots & \\
0 & & 0
\end{array}\right]=I_{r} \oplus O,
$$

maka $A$ similar ke matriks $I_{r} \oplus O$, dan misalkan

$$
S^{-1} B S=\left[\begin{array}{ccc}
\beta_{1} & & \\
& \ddots & \\
& & \beta_{n}
\end{array}\right]=B_{1} \oplus B_{2},
$$

maka $B$ similar ke matriks $B_{1} \oplus B_{2}$. Selanjutnya $B_{1}$ dan $B_{2}$ keduanya dapat didiagonaliasi karena $B^{k+1}=B$. Perhatikan bahwa $S^{-1} B S=\operatorname{diag}\left(\beta_{1}, \cdots, \beta_{n}\right)$ untuk setiap $\beta_{i}{ }^{k+1}=\beta_{i}$ yaitu $\beta_{i}$ adalah akar-akar dari $\sqrt[k]{1}$ atau $\beta_{i}=0$. Misalkan $B_{1}=$ $\operatorname{diag}\left(\beta_{1}, \cdots, \beta_{r}\right)$ dan $B_{2}=\operatorname{diag}\left(\beta_{r+1}, \cdots, \beta_{n}\right)$, terdapat $\beta_{j} \neq 0$ untuk setiap $\beta_{j}=$ $\beta_{r+1}, \cdots, \beta_{n}$. 
Misalkan $c_{1} S^{-1} A S+c_{2} S^{-1} B S=S^{-1} C S$. Oleh karena $S^{-1} A S$ dan $S^{-1} B S$ keduanya diagonal, maka $S^{-1} C S$ juga diagonal. Misalkan

$$
S^{-1} C S=\left[\begin{array}{ccc}
\gamma_{1} & & \\
& \ddots & \\
& & \gamma_{n}
\end{array}\right]
$$

adalah matriks idempoten, maka nilai eigen dari $\gamma_{1}, \cdots, \gamma_{n}$ adalah 0 atau 1 . Selanjutnya dapat ditulis kombinasi linier dari $c_{1} S^{-1} A S+c_{2} S^{-1} B S=S^{-1} C S$ sebagai berikut.

$$
\begin{aligned}
\Longleftrightarrow & c_{1}\left(I_{r} \oplus O\right)+c_{2}\left(B_{1} \oplus B_{2}\right)=S^{-1} C S, \\
\Longleftrightarrow & c_{1} \operatorname{diag}(1, \cdots, 1,0, \cdots, 0)+c_{2} \operatorname{diag}\left(\beta_{1}, \cdots, \beta_{r}, \beta_{r+1}, \cdots, \beta_{n}\right) \\
& =\operatorname{diag}\left(\gamma_{1}, \cdots, \gamma_{r}, \gamma_{r+1}, \cdots, \gamma_{n}\right),
\end{aligned}
$$

dimana $\beta_{i} \in\{0\}$ atau $\beta_{i}$ adalah akar-akar dari $\sqrt[k]{1}, \gamma_{i} \in\{0,1\}$.

Oleh karena $c_{2}$ taknol dan $\beta_{r+1}, \cdots, \beta_{n}$ taknol, maka $\gamma_{r+1}=\cdots=\gamma_{n}=1$. Perhatikan bahwa persamaan (3.2) dapat diuraikan sebagai berikut

$$
\begin{aligned}
c_{1} \operatorname{diag}(1, \cdots, 1)+c_{2} \operatorname{diag}\left(\beta_{1}, \cdots, \beta_{r}\right) & \in\{0,1\}, \\
c_{2} \operatorname{diag}\left(\beta_{r+1}, \cdots, \beta_{n}\right) & =1 .
\end{aligned}
$$

Misalkan persamaan (3.2) adalah suatu sistem persamaan linier terhadap variabel $c_{1}$ dan $c_{2}$, maka untuk menyelesaikan sistem persamaan linier ini cukup dengan menggunakan dua buah persamaan yang saling bebas linier dimana $S^{-1} A S \neq 0$ dan asumsikan $S^{-1} B S$ memiliki setidaknya dua nilai eigen tak nol yang berbeda. Selanjutnya kemungkinan-kemungkinan yang muncul dari sistem persamaan linier akan dijelaskan dengan enam kasus berikut.

\section{Kasus 1.}

Misalkan diambil dua bentuk persamaan linier dari persamaan (3.2) sebagai berikut $c_{1}+c_{2} u=1, c_{1}+c_{2} v=0$.

Dengan melakukan metode eliminasi didapatkan nilai

$$
c_{1}=\frac{v}{v-u} \text { dan } c_{2}=\frac{1}{u-v} .
$$

Kemudian nilai $c_{1}$ dan $c_{2}$ disubtitusi ke persamaan (3.3) dan (3.4), sehingga

(1) $c_{1} \operatorname{diag}(1, \cdots, 1)+c_{2} \operatorname{diag}\left(\beta_{1}, \cdots, \beta_{r}\right) \in\{0,1\}$

$$
\frac{v}{v-u}+\frac{1}{u-v} \beta_{i} \in\{0,1\} \text {, untuk } i=1, \cdots, r \text {, maka } \beta_{i}=v \text { atau } \beta_{i}=u,
$$

(2) $c_{2} \operatorname{diag}\left(\beta_{r+1}, \cdots, \beta_{n}\right)=1$

$$
\frac{1}{u-v} \beta_{j}=1 \text { untuk } j=r+1, \cdots, n \text {, maka } \beta_{j}=u-v .
$$

Selanjutnya akan disusun nilai eigen dari matriks $S^{-1} A S$ dan $S^{-1} B S$ dengan dua kondisi yaitu untuk $r=n$ dan $r<n$.

1. Jika $r=n$, asumsikan bahwa $A$ dan $B$ similar secara simultan dengan matriks $A_{1} \oplus A_{2}$ dan $B_{1} \oplus B_{2}$ secara berturut-turut. Selanjutnya dipilih nilai eigen dari $S^{-1} B S$ yaitu $\beta_{i}=v$ atau $\beta_{i}=u$ dimana $u, v$ adalah akarakar dari $\sqrt[k]{1}$ untuk suatu $k=2,3, \cdots$. Terlihat bahwa $S^{-1} B S$ memiliki 
dua nilai eigen taknol yang berbeda, maka nilai eigen dari matriks $S^{-1} A S$ dan $S^{-1} B S$ disusun sebagai berikut

$$
S^{-1} A S=\left[\begin{array}{ll}
I & 0 \\
0 & I
\end{array}\right], S^{-1} B S=\left[\begin{array}{cc}
v I & 0 \\
0 & u I
\end{array}\right] .
$$

Sehingga kombinasi linier dari $c_{1} S^{-1} A S+c_{2} S^{-1} B S$ adalah

$$
\frac{v}{v-u}\left[\begin{array}{ll}
I & 0 \\
0 & I
\end{array}\right]+\frac{1}{u-v}\left[\begin{array}{cc}
v I & 0 \\
0 & u I
\end{array}\right]=\left[\begin{array}{ll}
0 & 0 \\
0 & I
\end{array}\right]
$$

yang memenuhi kombinasi linier pertama pada teorema.

2. Jika $r<n$ dan $k=6$, dimana $\varepsilon=\frac{1}{2} \pm \frac{\sqrt{3}}{2} i$ dan $u \neq v$. Asumsikan bahwa $A$ dan $B$ similar secara simultan dengan matriks $A_{1} \oplus O$ dan $B_{1} \oplus B_{2}$ secara berturut-turut. Selanjutnya $\beta_{j}=u-v$ dibuat menjadi $u=\beta_{j}+v$, sehingga $\beta_{j}=\varepsilon u$ dan $v=\varepsilon^{-1} u$ dimana $u, \beta_{j}, v$ adalah akar-akar dari $\sqrt[6]{1}$, maka nilai eigen dari matriks $S^{-1} A S$ dan $S^{-1} B S$ disusun sebagai berikut

$$
S^{-1} A S=\left[\begin{array}{lll}
I & 0 & 0 \\
0 & I & 0 \\
0 & 0 & 0
\end{array}\right], S^{-1} B S=\left[\begin{array}{ccc}
\varepsilon^{-1} u I & 0 & 0 \\
0 & u I & 0 \\
0 & 0 & \varepsilon u I
\end{array}\right]
$$

dan $c_{1}=\frac{v}{v-u}=\varepsilon, c_{2}=\frac{1}{u-v}=\varepsilon^{-1} u^{-1}$.

Sehingga kombinasi linier dari $c_{1} S^{-1} A S+c_{2} S^{-1} B S=S^{-1} C S$ adalah

$$
\varepsilon\left[\begin{array}{lll}
I & 0 & 0 \\
0 & I & 0 \\
0 & 0 & 0
\end{array}\right]+\varepsilon^{-1} u^{-1}\left[\begin{array}{ccc}
\varepsilon^{-1} u I & 0 & 0 \\
0 & u I & 0 \\
0 & 0 & \varepsilon u I
\end{array}\right]=\left[\begin{array}{lll}
0 & 0 & 0 \\
0 & I & 0 \\
0 & 0 & I
\end{array}\right]
$$

yang memenuhi kombinasi linier ke-5 pada teorema.

\section{Kasus 2.}

Misalkan diambil dua bentuk persamaan linier dari persamaan (3.2) sebagai berikut $c_{1}+c_{2} u=1, c_{1}+c_{2} v=1$ dimana $(u \neq v)$.

Dengan melakukan metode eliminasi, di dapatkan nilai $c_{2}=0$. Kasus ini tidak memenuhi asumsi 3 dimana $c_{1} \neq 0 \neq c_{2}$.

\section{Kasus 3.}

Misalkan diambil dua bentuk persamaan linier dari persamaan (3.2) sebagai berikut $c_{1}+c_{2} u=0, c_{2} v=1$.

Dengan melakukan metode eliminasi didapatkan nilai $c_{1}=-u v^{-1}$ dan $c_{2}=v^{-1}$.

Kemudian nilai $c_{1}$ dan $c_{2}$ disubtitusi ke persamaan (3.3) dan (3.4) sehingga

(1) $c_{1} \operatorname{diag}(1, \cdots, 1)+c_{2} \operatorname{diag}\left(\beta_{1}, \cdots, \beta_{r}\right) \in\{0,1\}$ $-u v^{-1}+v^{-1} \beta_{i} \in\{0,1\}$, untuk $i=1, \cdots, r$, maka $\beta_{i}=u$ atau $\beta i=u+v$,

(2) $c_{2} \operatorname{diag}\left(\beta_{r+1}, \cdots, \beta_{n}\right)=1$ $v^{-1} \beta_{j}=1$ untuk $j=r+1, \cdots, n$, maka $\beta_{j}=v$.

Asumsikan bahwa $A$ dan $B$ similar secara simultan dengan matriks $I_{r} \oplus O$ dan $B_{1} \oplus B_{2}$ secara berturut-turut. Selanjutnya akan disusun nilai eigen dari matriks $S^{-1} A S$ dan $S^{-1} B S$ dengan tiga kondisi yaitu jika dipilih $\beta_{i}=u, \beta_{i} \neq 0$, dan $\beta_{i}=0$. 
Keidempotenan Kombinasi Matriks Idempoten dan T-Poten yang Komutatif 147

1. Jika $\beta_{i}=u$ untuk semua $i=1, \cdots, r$, maka nilai eigen dari $S^{-1} A S$ dan $S^{-1} B S$ disusun sebagai berikut

$$
S^{-1} A S=\left[\begin{array}{ll}
I & 0 \\
0 & 0
\end{array}\right], S^{-1} B S=\left[\begin{array}{cc}
u I & 0 \\
0 & v I
\end{array}\right] .
$$

Sehingga kombinasi linier dari $c_{1} S^{-1} A S+c_{2} S^{-1} B S=S^{-1} C S$ adalah

$$
-u v^{-1}\left[\begin{array}{ll}
I & 0 \\
0 & 0
\end{array}\right]+v^{-1}\left[\begin{array}{cc}
u I & 0 \\
0 & v I
\end{array}\right]=\left[\begin{array}{ll}
0 & 0 \\
0 & I
\end{array}\right]
$$

yang memenuhi kombinasi linier ke-2 pada teorema.

2. Jika $\beta_{i} \neq 0$ dan $k=6$, maka $\beta_{i}=u+v$ dibuat menjadi $u=\varepsilon^{-1} \beta_{i}$ dan $v=\varepsilon \beta_{i}$ dimana $\beta_{i}, u, v$ adalah akar-akar dari $\sqrt[6]{1}$. Selanjutnya nilai eigen dari matriks $S^{-1} A S$ dan $S^{-1} B S$ disusun sebagai berikut

$$
S^{-1} A S=\left[\begin{array}{lll}
I & 0 & 0 \\
0 & I & 0 \\
0 & 0 & 0
\end{array}\right], S^{-1} B S=\left[\begin{array}{ccc}
\varepsilon^{-1} \beta_{i} I & 0 & 0 \\
0 & \beta_{i} I & 0 \\
0 & 0 & \varepsilon \beta_{i} I
\end{array}\right]
$$

dan $c_{1}=-u v^{-1}=\varepsilon, c_{2}=v^{-1}=\varepsilon^{-1} \beta_{i}^{-1}$.

Sehingga kombinasi linier dari $c_{1} S^{-1} A S+c_{2} S^{-1} B S=S^{-1} C S$ adalah

$$
\varepsilon\left[\begin{array}{lll}
I & 0 & 0 \\
0 & I & 0 \\
0 & 0 & 0
\end{array}\right]+\varepsilon^{-1} \beta_{i}^{-1}\left[\begin{array}{cccc}
\varepsilon^{-1} \beta_{i} I & 0 & 0 \\
0 & \beta_{i} I & 0 \\
0 & 0 & \varepsilon \beta_{i} I
\end{array}\right]=\left[\begin{array}{lll}
0 & 0 & 0 \\
0 & I & 0 \\
0 & 0 & I
\end{array}\right]
$$

yang memenuhi kombinasi linier ke-5 pada teorema.

3. Jika $\beta_{i}=0$ dan $k=2$, maka $u=-v, c_{1}=1$, dan $c_{2}=v^{-1}$. Selanjutnya nilai eigen dari $S^{-1} A S$ dan $S^{-1} B S$ disusun sebagai berikut

$$
S^{-1} A S=\left[\begin{array}{ccc}
I & 0 & 0 \\
0 & I & 0 \\
0 & 0 & 0
\end{array}\right], S^{-1} B S=\left[\begin{array}{ccc}
-v I & 0 & 0 \\
0 & 0 & 0 \\
0 & 0 & v I
\end{array}\right] \text {. }
$$

Sehingga kombinasi linier dari $c_{1} S^{-1} A S+c_{2} S^{-1} B S=S^{-1} C S$ adalah

$$
\left[\begin{array}{lll}
I & 0 & 0 \\
0 & I & 0 \\
0 & 0 & 0
\end{array}\right]+v^{-1}\left[\begin{array}{ccc}
-v I & 0 & 0 \\
0 & 0 & 0 \\
0 & 0 & v I
\end{array}\right]=\left[\begin{array}{lll}
0 & 0 & 0 \\
0 & I & 0 \\
0 & 0 & I
\end{array}\right]
$$

yang memenuhi kombinasi linier ke-4 pada teorema.

\section{Kasus 4.}

Misalkan diambil dua bentuk persamaan linier dari persamaan (3.2) sebagai berikut. $c_{1}+c_{2} u=0, c_{1}+c_{2} v=0$ dimana $(u \neq v)$.

Dengan melakukan metode eliminasi, di dapatkan nilai $c_{2}=0$. Kasus ini tidak memenuhi asumsi 3 dimana $c_{1} \neq 0 \neq c_{2}$.

\section{Kasus 5.}

Misalkan diambil dua bentuk persamaan linier dari persamaan (3.2) sebagai berikut $c_{1}+c_{2} u=1, c_{2} v=1$.

Dengan melakukan metode eliminasi didapatkan nilai $c_{1}=1-u v^{-1}$ dan $c_{2}=v^{-1}$.

Kemudian nilai $c_{1}$ dan $c_{2}$ disubtitusi ke persamaan (3.3) dan (3.4) sehingga 
(1) $c_{1} \operatorname{diag}(1, \cdots, 1)+c_{2} \operatorname{diag}\left(\beta_{1}, \cdots, \beta_{r}\right) \in\{0,1\}$

$1-u v^{-1}+v^{-1} \beta i \in\{0,1\}$, untuk $i=1, \cdots, r$, maka $\beta_{i}=u$ atau $\beta_{i}=u-v$

(2) $c_{2} \operatorname{diag}\left(\beta_{r+1}, \cdots, \beta_{n}\right)=1$

$$
v^{-1} \beta_{j}=1 \text { untuk } j=r+1, \cdots, n \text {, maka } \beta_{j}=v .
$$

Asumsikan bahwa $A$ dan $B$ similar secara simultan dengan matriks $I_{r} \oplus O$ dan $B_{1} \oplus B_{2}$ secara berturut-turut. Selanjutnya akan disusun nilai eigen dari matriks $S^{-1} A S$ dan $S^{-1} B S$ dengan dua kondisi yaitu jika dipilih $\beta_{i}=u$ dan $\beta_{i}=u-v$.

1. Jika $\beta_{i}=u$ untuk semua $i=1, \cdots, r$, maka nilai eigen dari $S^{-1} A S$ dan $S^{-1} B S$ disusun sebagai berikut.

$$
S^{-1} A S=\left[\begin{array}{ll}
I & 0 \\
0 & 0
\end{array}\right], S^{-1} B S=\left[\begin{array}{cc}
u I & 0 \\
0 & v I
\end{array}\right] .
$$

Sehingga kombinasi linear dari $c_{1} S^{-1} A S+c_{2} S^{-1} B S=S^{-1} C S$ adalah

$$
1-u v^{-1}\left[\begin{array}{ll}
I & 0 \\
0 & 0
\end{array}\right]+v^{-1}\left[\begin{array}{cc}
u I & 0 \\
0 & v I
\end{array}\right]=\left[\begin{array}{ll}
I & 0 \\
0 & I
\end{array}\right]
$$

yang memenuhi kombinasi linier ke-3 pada teorema.

2. Jika $\beta_{i}=u-v$ dan $k=6$, maka $\beta_{i}=u-v$ dibuat menjadi $u=\beta_{i}+v$, sedemikian sehingga $\beta_{i}=\varepsilon^{-1} u$ dan $v=\varepsilon u$ dimana $\beta_{i}, u, v$ adalah akar-akar dari $\sqrt[6]{1}$. Selanjutnya nilai eigen dari $S^{-1} A S$ dan $S^{-1} B S$ disusun sebagai berikut

$$
S^{-1} A S=\left[\begin{array}{lll}
I & 0 & 0 \\
0 & I & 0 \\
0 & 0 & 0
\end{array}\right], S^{-1} B S=\left[\begin{array}{ccc}
\varepsilon^{-1} u I & 0 & 0 \\
0 & u I & 0 \\
0 & 0 & \varepsilon u I
\end{array}\right]
$$

dan $c_{1}=1-u v^{-1}=\varepsilon, c_{2}=v^{-1}=\varepsilon^{-1} u^{-1}$.

Sehingga kombinasi linier dari $c_{1} S^{-1} A S+c_{2} S^{-1} B S=S^{-1} C S$ adalah

$$
\varepsilon\left[\begin{array}{lll}
I & 0 & 0 \\
0 & I & 0 \\
0 & 0 & 0
\end{array}\right]+\varepsilon^{-1} u^{-1}\left[\begin{array}{ccc}
\varepsilon^{-1} u I & 0 & 0 \\
0 & u I & 0 \\
0 & 0 & \varepsilon u I
\end{array}\right]=\left[\begin{array}{lll}
0 & 0 & 0 \\
0 & I & 0 \\
0 & 0 & I
\end{array}\right]
$$

yang memenuhi kombinasi linier ke-5 pada teorema.

\section{Kasus 6.}

Misalkan diambil dua bentuk persamaan linier dari persamaan (3.2) sebagai berikut. $c_{2} u=1, c_{2} v=0$ dimana $(u \neq v)$.

Dengan melakukan metode eliminasi didapatkan nilai $u=v$. Kasus ini tidak memenuhi teorema dimana $u \neq v$.

\section{Kesimpulan}

Berdasarkan pembahasan pada tugas akhir ini dapat disimpulkan bahwa kombinasi linier $c_{1} S^{-1} A S+c_{2} S^{-1} B S$ adalah matriks idempoten dimana $A$ adalah matriks idempoten dan $B$ adalah matriks $t$-poten untuk $t>1$ jika dan hanya jika matriks $A$ dan $B$ komutatif, sehingga $c_{1} S^{-1} A S+c_{2} S^{-1} B S=S^{-1} C S$ adalah salah satu dari lima bentuk kombinasi linier berikut. 
1) $\frac{v}{v-u}\left[\begin{array}{ll}I & 0 \\ 0 & I\end{array}\right]+\frac{1}{u-v}\left[\begin{array}{cc}v I & 0 \\ 0 & u I\end{array}\right]=\left[\begin{array}{ll}0 & 0 \\ 0 & I\end{array}\right]$

2) $-u v^{-1}\left[\begin{array}{ll}I & 0 \\ 0 & I\end{array}\right]+v^{-1}\left[\begin{array}{cc}u I & 0 \\ 0 & v I\end{array}\right]=\left[\begin{array}{ll}0 & 0 \\ 0 & I\end{array}\right]$,

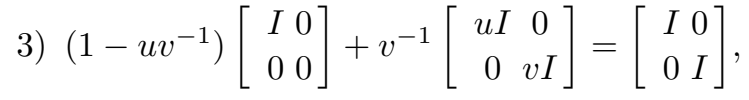

4) $\left[\begin{array}{lll}I & 0 & 0 \\ 0 & I & 0 \\ 0 & 0 & 0\end{array}\right]+v^{-1}\left[\begin{array}{ccc}-v I & 0 & 0 \\ 0 & 0 & 0 \\ 0 & 0 & v\end{array}\right]=\left[\begin{array}{lll}0 & 0 & 0 \\ 0 & I & 0 \\ 0 & 0 & I\end{array}\right]$ jika $k=2$,

5) $\varepsilon\left[\begin{array}{lll}I & 0 & 0 \\ 0 & I & 0 \\ 0 & 0 & 0\end{array}\right]+\varepsilon^{-1} u^{-1}\left[\begin{array}{ccc}\varepsilon^{-1} u I & 0 & 0 \\ 0 & u I & 0 \\ 0 & 0 & \varepsilon u I\end{array}\right]=\left[\begin{array}{lll}0 & 0 & 0 \\ 0 & I & 0 \\ 0 & 0 & I\end{array}\right]$ jika $k=6$,

dimana $u, v$ adalah akar-akar dari $\sqrt[k]{1}$ untuk suatu $k, u \neq v$, dan $\varepsilon=\frac{1}{2} \pm \frac{\sqrt{3}}{2} i$.

\section{Daftar Pustaka}

[1] Anton, H dan C. Rorres. 2014. Elementery Linear Algebra, Aplications Version, 11th Edition. New York: Wiley.

[2] Brown, James Ward and Churchill. Ruel V. 2009. Complex Variables and Applications, 8th Edition. New York: McGraw-Hill.

[3] Horn, Roger A dan Johnson, Charles R. 2013. Matrix Analysis, Second Edition. Cambridge University Press.

[4] J. Benitez, N. Thome. 2005. Idempotency of Linear Combinations of an Idempotent Matrix and a T-Potent Matrix that Commute. Linear Algebra and it's Aplications, 403: $414-418$.

[5] J. Benitez, N. Thome. 2006. $\{K\}$-Group Periodic Matrices. SIAM J. Matrix Anal. Appl, Vol.28 No.1, pp. 9 - 25.

[6] J.K Baksalary, O.M. Baksalary. 2000. Idempotency of linear combinations of two idempotent matrices. Linear Algebra Appl. 321: 3 - 7.

[7] J.K Baksalary, O.M. Baksalary, G.P.H.Styan. 2002. Idempotency of linear combinations of an idempotent matrix and tripotent matrix. Linear Algebra Appl. 354: $21-34$.

[8] Lipschutz, S. and Lipson, M. 2009. Linear Algebra, $4^{\text {th }}$ Edition. Schaum's Outlines.

[9] Poularikas, Ed. Alexander. D. 1999. The Handbook of Formulas and Tables for Signal Processing. Boca Raton: CRC Press LLC. 